\title{
SUBARACHNOID BLOCK; COMPARISON OF EFFICACY OF PHENYLEPHRINE VERSUS EPHEDRINE IN THE TREATMENT OF HYPOTENSION DURING SUBARACHNOID BLOCK IN C-SECTION.
}

1. MBBS, MCPS

Medical Officer Anaesthesia Children Hospital and Institute of Child Health Multan

2. MBBS, FCPS

Assistant Professor of Anaesthesia Nishtar Institute of Dentistry Multan.

3. MBBS, FCPS

Assistant Professor of Anaesthesia

Children Hospital and

Institute of Child Health Multan

4. MBBS, FCPS

Woman Medical Officer

Nishtar Hospital Multan.

Correspondence Address:

Dr. Aamir Furqan

Assistant Professor of Anaesthesia Nishtar Institute of Dentistry Multan. draamir2009@hotmail.com

Article received on:

15/02/2017

Accepted for publication:

15/08/2017

Received after proof reading:

$03 / 11 / 2017$
Syed Hassan Nabeel ${ }^{1}$, Aamir Furqan ${ }^{2}$, Aatir Fayyaz ${ }^{3}$, Rahat Akhtar ${ }^{4}$

ABSTRACT... Introduction: Subarachnoid block has been in practice for below umbilical surgery more than 110 years. ${ }^{1}$ in recent era all over the world most of cesarean sections are being done under subarachnoid block because of high mortality rate associated with general anesthesia due to failed intubation and aspiration pneumonia. Objectives: To compare the efficacy of phenylephrine versus ephedrine in the treatment of hypotension during cesarean section under subarachnoid block. Study Design: Randomized control trial. Setting: Department of Anesthesiology Nishter Hospital Multan. Period: March 2014 to August 2014. Materials and Methods: A total 80 patients included in the study and patients were divided into two equal groups. Phenylephrine group ( $\mathrm{P}$ group) and Ephedrine group ( $\mathrm{E}$ group), 40 patients in each. Results: A total of $80(100 \%)$ patients included in the study. As concern to the age of patients, mean age in group E was 30.50 and standard deviation was 5.383 , similarly in group $P$ mean age was 30.75 and $S D$ was 5.921 . As concern to the efficacy in group $E, 7$ were having good efficacy and 33 were have poor efficacy. In group P 30 had good efficacy and 10 had poor efficacy. $P=0.000$ a significant value. Conclusion: Phenylephrine is more effective than ephedrine for the treatment of hypotension due to subarachnoid block during cesarean section.

Key words: $\quad$ Cesarean Section, Spinal Anaesthesia, Subarachnoid Block, Phenylephrine, Ephedrine.

Article Citation: Nabeel SH, Furqan A, Fayyaz A, Akhtar R. Subarachnoid Block; Comparison of efficacy of phenylephrine versus ephedrine in the treatment of hypotension during subarachnoid block in C-Section. Professional Med $\mathrm{J}$ 2017;24(11):1708-1712. DOI:10.17957/TPMJ/17.3887

\section{INTRODUCTION}

Subarachnoid block has been in practice for below umbilical surgery more than 110 years. ${ }^{1}$ in recent era all over the world most of cesarean sections are being done under subarachnoid block because of high mortality rate associated with general anesthesia due to failed intubation and aspiration pneumonia. ${ }^{1}$ But subarachnoid block is also associated with complications like, hypotension, bradycardia, tachycardia, high spinal, nausea, vomiting and even cardiac arrest.

Hypotension during subarachnoid block in cesarean section has detrimental effects both on mother and fetus including decrease uterine blood flow, fetal acidosis, and maternal symptoms of low cardiac output such as nausea, vomiting, dizziness, and loss of consciousness. ${ }^{2,3}$

In cesarean section, under subarchnoid block the most common complication is hypotension with a reported indicence greater than $80 \%{ }^{4}$ Hypotension may occur even after left uterine displacement and preloading with crystalloid. ${ }^{4,5}$ The severity of hypotension depends on the degree of aorto-caval compression syndrome, the amount of crystalloid preloading, doses of local anesthetic drugs administered. ${ }^{1}$ The most effective treatment of hypotension associated with cesarean section under subarachnoid block is the administration of vasopressor drugs. ${ }^{6}$

There are many vasopressors which can be used to treat spinal induced hypotension. Ephedrine is considered very effective in restoring maternal blood pressure after hypotension. But its superiority over other vasopresssors is not clearly defined. ${ }^{7}$ Ephedrine acts directly as well as indirectly. The second drug to treat hypotension in cesarean section under subarachnoid block is phenylephrine. It has pure alpha agonist effects. Although phenylephrine is not so commonly 
used to treat hypotension, results of several trials have suggested that phenylephrine has the same efficacy for preventing and treating hypotension in cesarean section under subarachnoid block as ephedrine. . $^{7,9,9,10,11}$

Magalhaes E, Goveia CS, de Araujo Ladeira LC, Nascimento BG, Kluthcouski SM in their study concluded that Hypotension had an incidence of 70\% in Group E (Ephedrine ) and 93\% in Group P (phenylephrine) $(p<0.05) .^{12}$

Hypotension may be a life threatening condition for patients undergoing cesarean section under subarachnoid block. So, this study will show which drug (either the phenylephrine or ephedrine) is better for controlling hypotension due to subarachnoid block during lower segment cesarean section. Results will be utilized to formulate the guidelines for the usage of preferred drug for the said purpose.

\section{MATERIALS AND METHODS}

The study was conducted after the approval of hospital ethical committee. All the patients admitted for elective lower segment cesarean section who fulfill the inclusion criteria were included in the study. An informed and written consent was taken for the use of their data for study purpose. Patients were divided into 2 groups i.e; Group E (Ephedrine group) and Group p (phenylephrine group) using lottery method. Ephedrine was prepared as $5 \mathrm{mg}$ and phenylephrine as $50 \mathrm{mg}$ in the same type and size of syringes by an anesthetist who was not involved in study. Researcher and patient were blinded in the study.

On day of operation patients were monitored using standard monitoring NIBP, ECG and pules-oximetry, and baseline parameters were recorded. Two brannulas $18 \mathrm{G}$ and $20 \mathrm{G}$ were inserted on both hands and patient was preloaded with colloid solution $10 \mathrm{ml} / \mathrm{kg}$, which was given in 15-20 minutes. Using aseptic measures the subarachnoid block was performed with $27 \mathrm{G}$ nontraumatic needle at the level of L4-5 or L3-4 intervertabral space and hyperbareic Bupivicain $0.75 \% 1.5 \mathrm{ml}$ was administered intrathecally. Then patient was returned to left tilted supine position. 4-6L/min. Oxygen was given by transparent face mask. Blood pressure was monitored at 5 minutes interval beginning 5 minutes after subarachnoid block for 20 mins and when hypotension occur 1cc of the drug was injected I/V by researcher. $1 \mathrm{~min}$ after I/V drug injection blood pressure was again taken and efficacy of the drug was noted on the performa as described in operational definition. Hypotension was labeled as fall in blood pressure $20 \%$ below baseline. Efficacy was measured in terms of return of blood pressure to baseline or near baseline i.e, $80 \%$ or $90 \%$ towards baseline. Randomization was performed by lottery method. Intraoperative fluids were given at the rate of $25 \mathrm{ml} / \mathrm{min}$. Drug was considered effective if systolic blood pressure raised to baseline systolic blood pressure within 1 min after administration of either drug i.e; phenylephrine or ephedrine. Pregnant females between ages of 22-40 years, ASA 1 and 2 patients, Gestational amenorrhea of $>32$ weeks, Elective cesarean section, Patient willing for spinal anesthesia. Singleton pregnancy with cephalic presentation. Baseline systolic blood pressure between 100-140 $\mathrm{mmHg}$ and diastolic blood pressure between $70-89 \mathrm{mmHg}$ were included in the study. Any contraindication to spinal anesthesia i.e. local infection at the site of injection, valvular heat diseases, bleeding tendency, any co-morbidity like diabetes mellitus, liver cirrhosis, renal failure etc, any obstetric complications like placenta previa, pregnancy induced hypertension or HELLP syndrome, multiple gestation, fetal malformation, coagulopathies, morbid obesity and spine deformity were excluded from the study. After the completion of study, data was entered in SPSS 20 and analyzed. All the numerical data including age weight and height of the patients, were presented as mean and standard deviation. The efficacy of drug-was compared using Chi-Square test Values of $P$ less than 0.05 was considered statistically significant. The confounding variables were controlled by following exclusion criteria and stratification, based on age and height.

\section{RESULTS}

A total of $80(100 \%)$ patients included in the study. As concern to athe age of patients, mean 
age in group $E$ was 30.50 and standard deviation was 5.383 , similarly in group $P$ mean age was 30.75 and SD was 5.921 (Table-I). As regard to the weight mean weight in group $E$ was 56.65 ans SD 6.351, in group P mean weight was 58.50 and SD 5.383 (Table-I). Mean height of patients in group E was 153.65 and SD was 6.351 , similarly in group $P$ mean height was 155.50 and $S D$ was 5.383 (Table-I). As concern to the parity, out of 80 (100\%), 57 (71.2\%) were primipara and 23 (28.8\%) were multipara (Table-II). As regard to the gravida out of $80(100 \%), 30(37.5 \%)$ were primigravida and $50(62.5 \%)$ were multigravida (Table-II). Out of $80(100 \%), 37(46.2 \%)$ were have good efficacy and 43 (53.8\%) were have poor efficacy (TableII). On cross tabulation it's clear that in group E, 37 patients were primipara and 3 were multipara. Similarly in group $P, 20$ were primipara and 20 were multipara. $P$ value was 0.000 which is significant value (Table-II). In group E 17 was primigravida and 32 were multigravida, in group $P 13$ were primigravida and 27 were multigravida. $\mathrm{P}=3.55$ not a significant value (Table-II). As concern to the efficacy in group $E, 7$ were having good efficacy and 33 were have poor efficacy. In group $P 30$ were have good efficacy and 10 were have poor efficacy. $P=0.000$ a significant value (Table-II).

\begin{tabular}{|c|c|c|c|}
\hline $\begin{array}{c}\text { Chara- } \\
\text { cteristics }\end{array}$ & $\begin{array}{c}\text { Mean } \pm \text { SD } \\
\text { Group E }\end{array}$ & $\begin{array}{c}\text { Mean } \pm \text { SD } \\
\text { Group P }\end{array}$ & $\begin{array}{c}\text { P } \\
\text { Value }\end{array}$ \\
\hline Age & $30.50 \pm 5.383$ & $30.75 \pm 5.921$ & 0.000 \\
\hline Height & $153.65 \pm 6.351$ & $155.50 \pm 5.383$ & 0.000 \\
\hline Weight & $56.65 \pm 6.351$ & $58.50 \pm 5.383$ & 0.000 \\
\hline & Table-l. Demographic variables \\
\hline
\end{tabular}

\begin{tabular}{|l|c|c|c|}
\hline \multicolumn{1}{|c|}{$\begin{array}{c}\text { Chara- } \\
\text { cteristics }\end{array}$} & $\begin{array}{c}\text { Frequency } \\
\text { (percentage) } \\
\text { Group E } \\
\mathbf{n = 4 0}\end{array}$ & $\begin{array}{c}\text { Frequency } \\
\text { (percentage) } \\
\text { Group P } \\
\mathbf{n = 4 0}\end{array}$ & $\begin{array}{c}\text { P } \\
\text { Value }\end{array}$ \\
\hline Parity & $37(92.5 \%)$ & $3(7.5 \%)$ & \multirow{2}{*}{0.000} \\
\hline Primipara & $20(50 \%)$ & $20(50 \%)$ & \\
\hline Multipara & \multicolumn{2}{|c|}{0.000} \\
\hline Gravidity & $17(42.5 \%)$ & $23(57.5 \%)$ & \\
\hline Primary gravida & $13(32.5 \%)$ & $27(67.5 \%)$ & \multirow{2}{*}{0.000} \\
\hline Multigravida & $7(17.5 \%)$ & $30(75 \%)$ & \\
\hline Efficacy & $33(82.5 \%)$ & $10(25 \%)$ & \\
\hline Good & & & \\
\hline Poor & & & \\
\hline Total & & & \\
\hline
\end{tabular}

Table-II. Inferential results

\section{DISCUSSION}

In our study, we showed that there was a mark able difference between phenylephrine and ephedrine in their efficacy for managing hypotension in healthy parturient under-going cesarean section.

The treatment and prevention of maternal hypotension-induced spinal anesthesia remains the most important dilemma, with no agreement to the optimal mode of management. ${ }^{13}$ Clinical data have suggested that a-adrenergic agonists such as phenylephrine or ephedrine may be given safely for prevention or treatment of hypotension during administration of regional anesthesia for cesarean section. Previous studies have confirmed the beneficial phenylephrine effects on umbilical $\mathrm{pH}$, as phenylephrine has been recently the first line drug for this rationale. ${ }^{14}$ However, more up to date studies results show that some caution with the use of phenylephrine may be warranted.

Even though phenylephrine is effective for managing blood pressure, it may cause reflexes bradycardia and it may reduce cardiac output. The clinical importance is more reduction of utero-placental blood flow. ${ }^{15}$ Ephedrine is also associated with tachycardia. For reducing the cardiac effects of vasopressors, Ngan Kee et al. ${ }^{16}$ investigated the combination of ephedrine and phenylephrine in different ratios administered by infusion. They found combination of vasopressors seem to have no advantage compared with phenylephrine alone. Loughey et al. have been noted that the combination of two vasopressors is not superior to ephedrine alone.

In contrast to the past studies, a recent study described that phenylephrine was associated with higher values of fetal lactate. ${ }^{17}$ There is proof that fetal lactate may be a better predictor of severe neonatal morbidity than $\mathrm{PH}$. In the later study by $\mathrm{Ngan} \mathrm{Kee}^{18}$ et al., they compared the ephedrine with phenylephrine in non-elective cesarean section. Their conclusion was that despite small differences between groups in umbilical cord blood lac- tate concentration and $\mathrm{PO} 2$, there were no differences in fetal acid-base status or clinical neonatal outcome be- tween 
the two vasopressors. Our current study results relatively conform to the $\mathrm{Ngan} \mathrm{Kee}^{18}$ study.

In this study, for two reasons, we did not administer vasopressors as prophylaxis. Firstly, it is not ethically right; for instance we could not administer ephedrine to a patient who had tachycardia. Secondly, clinical studies are not in support of prophylactic use of vasopressors for prevention of spinal hypotension.

The main cause for rescue vasopressor use in most studies was hypotension. The trigger for rescue IV vasopresor use in our study was not only $20 \%-30 \%$ reduction in SAP, but also the present heart rate changes secondary to sympathetic blockade of spinal anesthesia. This is usual practice for treatment of hypotension in our ward.

Two patients of pheny- lephrine group vs. five patients of the ephedrine group had nausea. Nausea and vomiting may be due to the level of hypotension that was similar in two groups, and may be related to the faster response time to vasopressors. ${ }^{18}$ In our study there was no significant difference in this term between two groups.

The bolus doses of phenylephrine (50 mg) and ephedrine (5 mg) used in our study was determined empirically. Bases on our clinical experience and Prakash et al. study, we chose these doses. Although Saravanon et al. demonstrated a potency ratio of $80: 1$ (100 $\mu \mathrm{g}$ phenylephrine $\sim 10 \mathrm{mg}$ ephedrine) for equivalence between phenylephrine and ephedrine as infusion in prevention of hypotension induced spinal anesthesia. Prakash et al. compared the efficacy of phenylephrine $100 \mu \mathrm{g}$ and ephedrine $6 \mathrm{mg}$ in the treatment maternal hypotension.

Total dose required for vasopressors in current study was lower than the previous studies. The relatively small doses of vasopressors used in our study may elaborate the finding that umbilical blood gases values were not significantly different in two groups. Ephedrine- induced fetal acidosis appears to be associated both with the total dose of ephedrine given before delivery and with the duration of fetal exposure to ephedrine, not with hypotension. In this study duration of fetal exposure to vasopressors is less because we used those drugs for treatment (not prophylaxis) of hypotension. These results are agreement with other observations previously re- ported in the literatures.

\section{CONCLUSION}

Phenylephrine is more effective than ephedrine for the treatment of hypotension due to subarachnoid block during cesarean section.

Copyright(C) 15 Aug, 2017.

\section{REFERENCES}

1. Ganeshanvar A, Ramesh K, Ravi R, Adrash ES, Uday Ambi S. Co, parison of Bolus phenylephrine, Ephedrine and Mephetemine for Maintenance of Areterial Pressure during spinal Anaesthesia in Caesarean Section. J Clin Diag Res, 2011; 5(5):948-52.

2. Loughery JPR, Yao N, data S, Segal S, pian-smith M, Tsen LC. Hemodynamic effects of spinal anesthesia and simultaneous intravenous bolus of combined phenylephrine and ephedrine versus ephedrine for cesarean delivery. In t J Obstet Anesth, 2005; 14:4347.

3. Rasanen J, Alahuhtat S, Kangas-Saarelat T, jouppliat R, jouppila $p$. The effects of ephedrine and etilefrine on utrine and fetal flood flow and on fetal myocardial function during spinal anesthesia for cesarean section. Int J Obstest Anesth, 1991; 1:3-8.

4. Kol IO, Kaygussuz K, Gursoy S, Cetin A, Kaharmanogly $Z$, Ozkan F, et al. The effects of intravenous ephedrine during spinal anesthesia for cesarean delivery: a randomized controlled trail. J Korean. Med Sci, 2009; 24(5):883-8.

5. Hennebry MC, Stocks GM, Belavdi P, Barnes S, Wray $S$, Cloumb Mo, let al. Effects of i.v. phenylephrine or ephedrine on ED50 of intrathecal bupivacanie with fetanly for cesarean section. $\mathrm{Br} J$ Anaesth, 2009; 102(6):806-11.

6. Adigun TA, Amanor-Badu SD, Soyannwo OA. Comparison of intravenous ephedrine with phenylephrine for the maintenance of arterial blood pressure during elective caesarian section under spinal anaesthesia. Afr J Med Med Sci, 2010; 39(1):1320.

7. Lee A, Ngan Kee WD, Gin T. A Quantitative, Systemic Review of Randomized Controlled Trials of Ephedrine 
Versus phenylephrine for the Management of Hypotension During spinal Anesthesia for Cesarean Delivery. Anesth Analg, 2002; 94:920-6.

8. Saravanan S, Kocarev M, Wilson RC, Watkins E, Columb $\mathrm{MO}$, Equivalent does of ephedrine and phenyleohrine in the prevention of post-spinal hypotension in Caesarean section. Br J Anaesth, 2006:96:95-9.

9. Tanaka M, Balki M, Parkes RK, Carvalho JCA. ED95 of phenylephrine to prevent spinal-induced hypotension and/or nausea at elective cesarean deilivery. Int J Obstet Anesth, 2009; 18:125-30.

10. Allen TK, Muir HA, George RB, Habib AS. A survey of the management of spinal-induced hypertension for scheduled cesarean delivery. Int J Obstet Anesth, 2009; 18:356-61.

11. Simin A, Zahra F, Pouya HM, Reza T. Comparison the effect of ephedrine and and phenylephrine in treatment of hypotension after spinal anesthesia during cesarean section. Open J Obstet Gynae, 2012; 2:192-6.

12. Magalhaes E, Goveia CS, de Araujo Ladeira LC, Nascimento BG, Kluthcouski SM. Ephedrine versus phenylephrine: prevention of hypotension during spinal block for cesarean and effects on the fetus. Rev Bars Anestesiol. 2009 Jan-Feb: 59 (1):11-20.

13. Ayorinde BT, Buczkowski P, Brown J, Shah J. Buggy, DJ. Evaluation of pre-emptive intra- muscular phenylephrine and ephedrine for reduction of spinal anaesthesia-induced hypotension during caesarean section. British Journal of Anaesthesia. 2001; 86:372-6.

14. Tanaka, M, Balki, M, Parkes RK, Carvalho JCA. ED95 of phenylephrine to prevent spinal-induced hypotension and/or nausea at elective cesarean delivery. International Journal of Obstetric Anesthesia. 2009; 18:125-30.

15. Ngan Kee, W.D. Prevention of maternal hypo- tension after regional anaesthesia for caesarean section. Current Opinion in Anaesthesiology. 2010; 23:304-9.

16. Prakash, S, Pramanik, V, Chellani, H, Salhan, S, Gogia, A.R. Maternal and neonatal effects of bolus administration of ephedrine and phenylephrine during spinal anaesthesia for caesarean delivery: A ran- domised study. International Journal of Obstetric Anes- thesia. 2010; 19:24-30.

17. Erkinaro T, Kavasmaa T, Pakkila M, Acharya G, Makikallio $\mathrm{K}$, Alahuhta $\mathrm{S}$ et al. Ephedrine and phenylephrine for the treatment of ma- ternal hypotension in a chronic sheep model of increased placental vascular resistance. British Journal of An- aesthesia. 2006; 96:231-7.

18. Ngan Kee WD, Khaw KS, Lau TK, Ng FF, Chui K, Ng et al. Randomized double-blinded comparison of phenylephrine vs ephedrine for maintaining blood pressure anaesthesia for non-elective caesarean section. Anaesthesia. 2008; 63:1319-26.

\begin{tabular}{|c|l|l|l|}
\hline \multicolumn{3}{|c|}{ AUTHORSHIP AND CONTRIBUTION DECLARATION } \\
\hline Sr. \# & \multicolumn{1}{|c|}{ Author-s Full Name } & \multicolumn{1}{|c|}{ Contribution to the paper } & Author=s Signature \\
\hline 1 & Syed Hassan Nabeel & Conceive idea, Design Study \\
2 & Aamir Furqan & Manuscript Writing \\
3 & Aatir Fayyaz & Data collection \\
\hline 4 & Rahat Akhtar & Data analysis, Proof Reading \\
\hline
\end{tabular}

